\title{
A volume deformation model for brittle rock based on fractional order calculus
}

\author{
Mingming He, Ning Li, Yunsheng Chen, Caihui Zhu \\ Institute of Geotechnical Engineering, Xi'an University of Technology, 710048, Xi'an, China, \\ E-mail:807658619@qq.com
}

cross ${ }^{\text {ref }}$ http://dx.doi.org/10.5755/j01.mech.23.4.15119

\section{Introduction}

The characteristics of rock masses play a key role in the long-term stability of geotechnical engineering. To understand deformation properties of rock as engineering materials, it is necessary to start with the behavior of intact rock. In the past few years, greater attention is focused on the deformation behavior of rock under varying loading scenarios. The reported literature has shown that there has been some progress in the description of the deformation behavior of rock [1-3].

For rock engineering, understanding the deformation behavior of brittle rock is much necessary due to the important influence on brittle rock characteristics and the safety of rock engineering. In recent, deformation problem of brittle rock has drawn much attention of researchers [4-6]. Liu et al [4] carried out a series of laboratory tests to assess the effects of confining pressure on the mechanical properties and deformation evolution of brittle rock samples subjected to cyclic loading. Results from the tests indicated that the level of confining pressure had a significant influence on the deformation evolution of the sandstone samples tested. Lajtai et al [5] investigated the effect of strain rate on deformation for brittle limestone ductile salt rock. The results showed an increase in compressive deformation with increasing strain and stressing rate, although the rate effect was very small. Chen [6] presented a non-local analysis of the dynamic damage accumulation processes in brittle solids. The results indicated that the model reproduced, qualitatively, the brittle behaviour of rock under blasting conditions. However, the volume deformation of brittle rock can reveal very abnormal phenomena even under the condition of compression and tension. Many changes of volume deformation are so strange that its mechanism is still unclear. For example, during the beginning stage of a constant-strain-rate tension, the volume strain shows a small reduction, which is beyond understanding because on the base of the classical mechanics there could be not the reduction of volume strain in stretching process. Though a large number of tests have been done to investigate the abnormal phenomena on polyethylene [7-9], little attention was paid to the mechanism analysis of the abnormal phenomena on brittle rock mentioned above.

In elastic mechanics using Poisson's ratio and axial strain to calculate volume strain is the most common method for brittle rock. However, it is shown that the Poisson's ratio formula is also complicated and rarely has successful application [10], which implies that using the Poisson's ratio to describe the volume strain is not a satisfactory approach. The volume strain of brittle rock shows a strong time dependent nature, while it is proven that the fractional calculus could accurately describe the complex physical process having memory and the time dependence, and the fractional models enjoy the advantage of having fewer parameters and simple form. Therefore, fractional calculus can be employed to study the complex volumetric deformation response in brittle rock.

Fractional calculus allows one to define precisely non-integer order integrals or derivatives. Nowadays, it has received considerable attention in the fields of electromagnetic [11], continuum mechanics [12], signal process [13-15], dynamics [16, 17], and other fields [18-20]. The application of viscoelasticity is regarded as the most successful one. For example, a series of researches on viscoelastic dampers have been finished by Park [21], Lewandowski [22] and Rossikhin [23-26]. In other cases, for a viscoelastic fluid, Shan [27], Ezzat [28] and Mahmood [29] have employed fractional calculus in their studies. However, these efforts were more focused on the stress-strain-time relationship and until now it is still unclear whether fractional calculus can be used to represent the volume strain.

In this paper, firstly the mechanism of complicated volume strain in brittle rock is analyzed by the viscoelastic theory. Then, we present a fractional viscoelastic volume strain model and the volume strain formulas are derived under a constant-strain-rate loading, respectively. At last, some experimental data of complex volume deformation in the tension and triaxial compression of brittle rock are employed to check the model.

\section{The fractional volume strain model}

\subsection{Basics of fractional calculus}

A fractional calculus can be defined by different ways, among which is the Riemann-Liouville fractional calculus. Definition 1. The Riemann-Liouville fractional integral of the function $f(t)$ with the order $r \in(0,1)$ is defined by [30]:

$$
D^{-r} f(t)=\frac{d^{-r}[f(t)]}{d t^{-r}}=\frac{1}{\Gamma(r)} \int_{0}^{t} f(t-\tau)^{r-1} f(\tau) d \tau,
$$

where $\Gamma(\cdot)$ is the gamma function, i.e., $\quad \Gamma(r)=\int_{0}^{\infty} t^{r-1} e^{-t} d t$. Definition 2. The fractional derivative of the function $f(t)$ 
with the order $r \in(a-1, a)$ of the function $f(t)$ is defined by [30]:

$$
D^{r} f(t)=\frac{d^{a}}{d t^{a}} \frac{1}{\Gamma(a-r)} \int_{0}^{t} f(t-\tau)^{a-r-1} f(\tau) d \tau .
$$

Using Eqs. (1) and (2), we can obtain:

$$
\left.\begin{array}{l}
D^{-r} t^{a}=\frac{\Gamma(a+1)}{\Gamma(a+1+r)} t^{r+a}, \\
D^{r} t^{a}=\frac{\Gamma(a+1)}{\Gamma(a+1-r)} t^{a-r}, r>0, a>-1, t>0 .
\end{array}\right\}
$$

\subsection{The Abel dashpot: a fractional derivative element}

It is well known from viscoelastic theory that the deformation of brittle rock is controlled by elastic deformation and viscoelastic deformation. The total strain is stated as:

$$
\varepsilon=\varepsilon^{e}+\varepsilon^{v e},
$$

where $\varepsilon^{e}$ and $\varepsilon^{v e}$ are the strains of the Hooke body and the viscoelastic body, respectively. When subjected to an applied stress, brittle rock may be deformed by elastic deformation or viscoelastic deformation or both. Then, the total volume strain is stated as:

$$
\varepsilon_{v}=\varepsilon_{v}^{e}+\varepsilon_{v}^{v e},
$$

where, $\varepsilon_{v}^{e}$ and $\varepsilon_{v}^{v e}$ are the volume strains of the Hooke body and the viscoelastic body, respectively. Under tension or compression loading, the elastic deformation increases and leads to an increase or decrease in volume, while the viscoelastic deformation will decrease and result in a time-dependent volume shrinkage in accordance with the viscoelastic theory. In other words, when subjected to an applied loading, $\varepsilon_{v}^{e}$ could be positive or negative and $\varepsilon_{v}^{v e}$ is always negative, where the volume increase is positive. In short, when subjected to an applied stress, brittle rock may deform by the combined effects of elastic deformation and viscoelastic deformation, which are the basic causes of the complex volume deformation in brittle rock.

The volume strain-time curve of stress relaxation is similar to its stress-time line, which can be described by fractional model. Considering that $\varepsilon_{v}^{v e}$ is the sum of the responses to excitations imposed at all previous times and has time-dependent property, we characterize it through a fractional integral expression:

$$
\varepsilon_{v}^{v e}(t)=-\lambda \frac{d^{r} \varepsilon(t)}{d t^{r}}
$$

where $\lambda$ and $r$ are material constant and differential order, respectively. When $\varepsilon(t)=v_{o} t$, where $v_{o}$ represents constant strain rate, based on Eq. (3) and Eq. (6) can be expressed as:

$$
\varepsilon_{v}^{v e}(t)=-\lambda \frac{v_{o} t^{1-r}}{\Gamma(2-r)},
$$

It should be noted that we put a negative sign on the right side of Eq. (7) because the volume variation is always decreasing under the condition of tension or compression.

\subsection{Volume deformation model}

It is well known the constitutive relation of generalized Hooke's law is written as:

$$
\left[\begin{array}{l}
\varepsilon_{1}=\frac{1}{E}\left[\sigma_{1}-v\left(\sigma_{2}+\sigma_{3}\right)\right]=\frac{1}{E}\left(\sigma_{1}-2 v \sigma_{2}\right), \\
\varepsilon_{2}=\varepsilon_{3}=\frac{1}{E}\left[\sigma_{2}-v\left(\sigma_{1}+\sigma_{3}\right)\right]=\frac{1}{E}\left[\sigma_{2}(1-v)-v \sigma_{1}\right], \sigma_{2}=\sigma_{3},
\end{array}\right.
$$

here $\sigma_{1}, \sigma_{2}, \varepsilon_{1}, \varepsilon_{2}, E$, and $v$, are the longitudinal stress of the Hooke body, the lateral stress, the longitudinal strain, the lateral strain, the Young's modulus, and the Poisson's ratio, respectively.

If $\sigma_{1} \neq 0, \sigma_{2}=\sigma_{3}=0$, Eq. (8) is rewritten as:

$\varepsilon_{2}=-v \varepsilon_{1}$

If $\sigma_{1} \neq 0, \sigma_{2}=\sigma_{3} \neq 0$, Eq. (8) is rewritten as:

$\frac{\varepsilon_{2}}{\varepsilon_{1}}=\frac{\sigma_{2}(1-v)-v \sigma_{1}}{\sigma_{1}-2 v \sigma_{2}}$.

Assuming a constant $-\mu$ for the ratio of $\varepsilon_{2}$ to $\varepsilon_{1}, \mathrm{Eq}$. (9) and Eq. (10) can be rewritten as:

$$
\frac{\varepsilon_{2}}{\varepsilon_{1}}=-\mu=\left\{\begin{array}{lrl}
v, & \sigma_{2}=\sigma_{3}=0 \\
-\frac{\sigma_{2}(1-v)-v \sigma_{1}}{\sigma_{1}-2 v \sigma_{2}}, & \sigma_{2}=\sigma_{3} \neq 0 .
\end{array}\right.
$$

1. For the Hooke body $(\mathrm{H})$, the volume strain is rewritten as:

$$
\varepsilon_{v}^{e}=(1-2 \mu) \varepsilon_{1},
$$

2. Using Eq. (5), Eq. (7) and Eq. (12), the total volume strain is rewritten as:

$$
\left.\begin{array}{l}
\varepsilon_{v}=\varepsilon_{1}-2 \mu \varepsilon_{1}-\lambda \frac{v_{o}{ }^{r}}{\Gamma(2-r)} \varepsilon_{1}^{1-r} \\
\text { or } \\
\varepsilon_{v}=v_{o} t-2 \mu v_{o} t-\lambda \frac{v_{o} t^{1-r}}{\Gamma(2-r)} .
\end{array}\right\}
$$

Now, let us turn to discuss the meaning of $\lambda$ and $r$ in the fractional volume model. When $r$ is fixed, the larger $\lambda$ in Eq. (13) means the more volume strain variation, effected by the combined effects of variable viscous and elastic. $r$ represents the time dependence of the volume variation. The volume strain curves from Eq. (13) are plotted in Fig. 1. If $r>0$, the $r$ illustrates that there is one rapid volume variation from the combined effects in the initial phase of loading and the rate of volume change will be closer and closer to a constant with $r$ increased to 1 . While $r<0$, the $r$ illustrates that there is one slow volume increasing from the combined effects in the initial phase of loading. It is observed from Fig. 1 that under the 
conditions of tension and compression, $r>0$ and $r<0$, the volume strain is increasing with axial strain, which is obviously analogous to the experimental plots of volume strain during tension and compression.

If $-0.9<r<1$ and $\varepsilon>0$, a volume curve, shown in Fig. 1, may be plotted schematically based on Eq. (13). The shape of the curve in Fig. 1 illustrates that the fractional volume strain model can characterize the small compaction during the beginning stage of tension and compression. From the above analysis, we know that several complex volumetric deformations should be capable of being described by the fractional volume strain model. Of course, it requires further verification through a large number of tests.

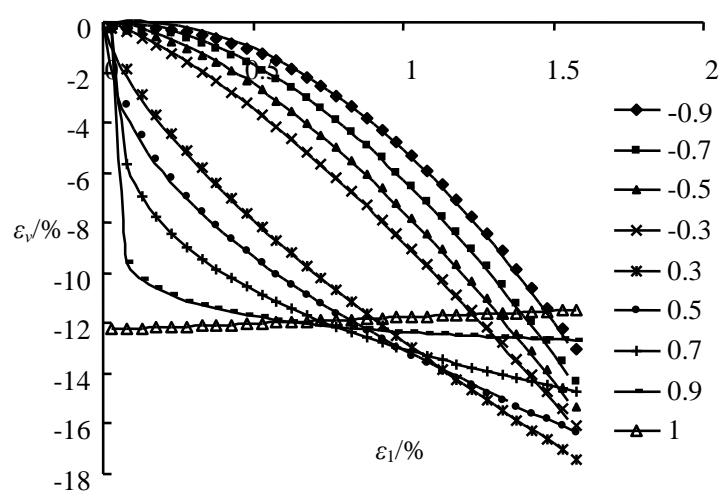

Fig. 1 Curves of $\varepsilon_{v}-\varepsilon_{1}$ under a constant longitudinal strain rate

\section{Experiment}

The tests were conducted on a WDT-1500 reactive material testing machine shown in Fig 2. The WDT-1500 controller consisted of hardware component and software applications. It consists of four parts: a DOLI's digital servo controller, a dynamic loading system, a self-balanced pressure chamber and a data acquisition system. The hydraulic station provides the power, the computer measurement and control system are used to control the electric-hydraulic servo valve, and the host runs the experiment under the control of the computer. The maximum axial force used was $1500 \mathrm{KN}$, the highest confining pressure applied was $80 \mathrm{MPa}$, the highest frequency was $10 \mathrm{~Hz}$, and the highest amplitude was $0.5 \mathrm{~mm}$.

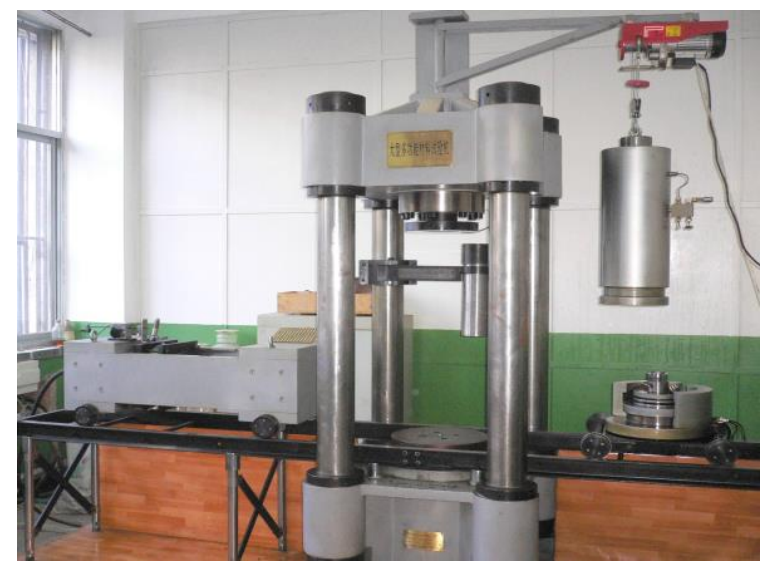

Fig. 2 WDT-1500 testing machine
To ensure the similarity of the tested samples as much as possible, as shown in Fig 3, the sandstone samples with almost the same content of impurity and without cracks were selected. The sandstone samples were cut into circular cylinders $50 \mathrm{~mm}$ diameter $\times 100 \mathrm{~mm}$ length, and the evenness of the head faces was controlled to $0.02 \mathrm{~mm}$. The samples were prechecked by ultrasonic means with a velocity limit of $3752 \pm 30 \mathrm{~ms}^{-1}$. Therefore, we assumed that the effect on the test results would be minimal. The brittleness $\lambda_{o}$ can be formulated as follows [31]:

$$
\lambda_{o}=\frac{\sigma_{c}-\sigma_{t}}{\sigma_{c}+\sigma_{t}}
$$

where $\sigma_{c}$ is the uniaxial compressive strength and $\sigma_{t}$ is the tensile strength. The obtained average uniaxial compressive strength and tensile strength are $75.42 \mathrm{MPa}$ and $6.15 \mathrm{MPa}$, respectively. Hence, the brittleness $\lambda_{o}$ is 0.849 .

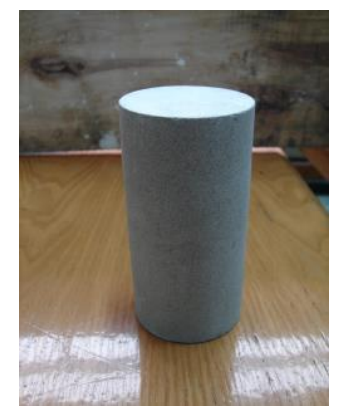

Fig. 3 Sandstone sample

To investigate the volume deformation properties of rock samples under different conditions, the samples were divided into three groups, each subjected to a different loading scheme: different confining pressures, different strain rates, and different temperatures. Tests were conducted on sandstone samples with confining pressures ranging from $0,5,10$ and $15 \mathrm{MPa}$, strain rates of $0.005 / \mathrm{s}, 0.0005 / \mathrm{s}$ and $0.0001 / \mathrm{s}$ and temperatures of $80^{\circ} \mathrm{C}$, $20^{\circ} \mathrm{C}$ and $-5^{\circ} \mathrm{C}$.

\section{Experimental results and model validation}

In this section, we have done a series of experiments in triaxial compression and uniaxial tension tests on brittle rock samples under the constant-strain-rate. During compression in different confining pressure and tension in different strain rate and different temperature, the volume strain is always characterizes negative and positive dilatancy shown in Fig. 4, Fig. 5 and Fig. 6. The fractional volume strain model will be validated by this experimental data.

\subsection{Triaxial compression tests under the constant longitudinal strain rate}

In order to check the fractional volume strain model, Eq. (13) is employed to fit some triaxial compression tests, in which the longitudinal strain rate is constant. We have done a series of experiments in triaxial compression on brittle rock samples. During compression in different confining pressure, the volume strain is always 
characterizes negative and positive dilatancy. The responding experimental results are revealed in Fig. 4. These test data are fitted by Eq. (13) and the fitting results are shown in Fig. 4. Clearly, the volume strain model can give relatively good simulations for the measured volume strain- longitudinal strain under triaxial compression. Moreover, it is discovered that the order $r$ increases with the increasing of confining pressure in the triaxial compression of the brittle rock samples.

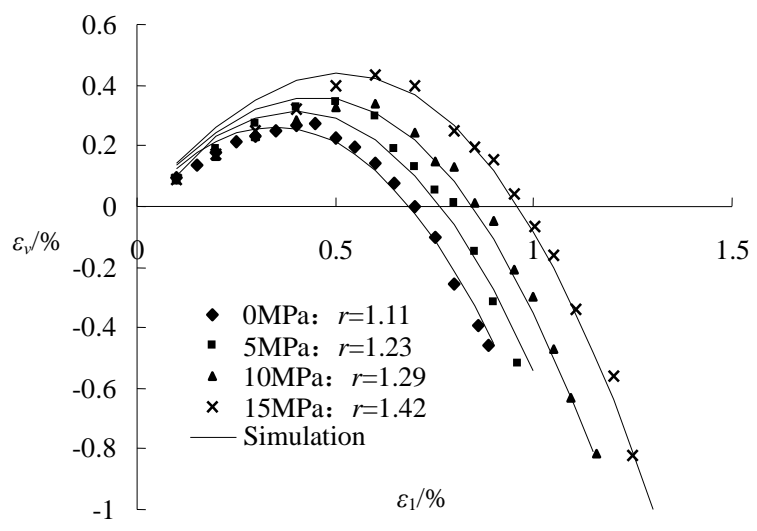

Fig. 4 Curves of $\varepsilon_{v}-\varepsilon$ for brittle rock samples at different confining pressures

4.2. Uniaxial tension tests under the constant longitudinal strain rate

The volume change under uniaxial constant -strain-rate tension is investigated at room temperature in brittle rock samples. The curves in Fig. 5 show the influence of strain rate on the volume strain. Also it is found from Fig. 5 that the volume strain depends on longitudinal strain rate, which implies that the dilatancy phenomena of volume deformation depend on longitudinal strain rate. From these experimental results, it is found that

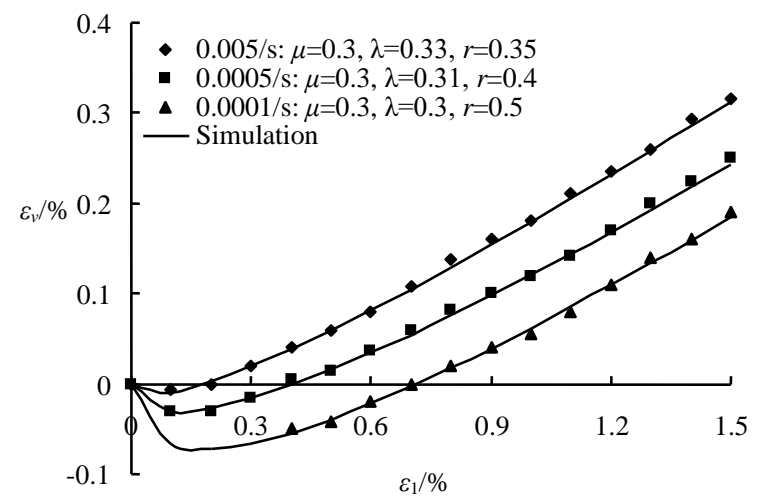

Fig. 5 Curves of $\varepsilon_{v}-\varepsilon_{1}$ curves for brittle rock samples at different strain rates

the negative dilatancy increase with the strain rate decreased, and the positive dilatancy decreasing. Eq. (13) is used to fit the experimental data of uniaxial tensile on brittle rock samples and the result is shown in Fig. 5. It is found that the volume strain model can depict the small volume compaction and the order $r$ increase with the strain rate decreased, which implies that the order is helpful to reveal the influence of strain rate on volume strain change. From these results, it is known that the volume strain model can depict the small compaction during the beginning stage of uniaxial tension.

The volume change under uniaxial constant -strain-rate tension is investigated at different temperatures in brittle rock samples. The curves in Fig. 6 show the influence of strain rate on the volume strain. Also it is found from Fig. 6 that the volume strain depends on temperature, which implies that the dilatancy phenomena of volume deformation depend on temperature. From these results, it is found that the negative dilatancy increase with temperature increasing, and the positive dilatancy decreasing. Eq. (13) is used to fit the experimental data of uniaxial tensile and the fitting result is shown in Fig. 6. It is discovered that the material constant $\lambda$ and $\mu$ change with temperature, which implies that the material constant is helpful to reveal the influence of temperature on volume strain change.

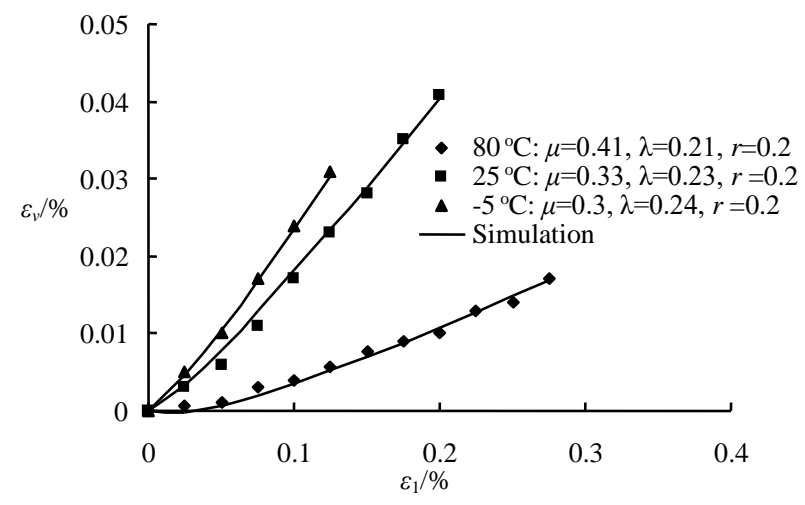

Fig. 6 Curves of $\varepsilon_{v}-\varepsilon$ for brittle rock samples at different temperatures

\section{Conclusion}

In this paper, we present experimental investigation of volume deformation properties of brittle rock samples in triaxial compression and uniaxial tension tests in different strain rate and different temperature in the laboratory. Through the viscoelasticity mechanics theory, and found that the combined effects of elastic deformation and viscoelastic deformation is the basic reason of causing the negative and positive dilatancy phenomena in the volume deformation of brittle rock. In order to describe accurately the volume deformation through a fractional model, volume strain model is presented, in which the variation of volume strain resulted from the combined effects is characterized through a fractional order calculus expression. Comparing with some test data, the results show that the fractional volume strain model can describe the dilatancy phenomena in the volume deformation of brittle rock.

\section{Acknowledgements}

The authors would like to acknowledge the financial support of National Natural Science Foundation of China (Grant no. 51179153 and no. 51308456) and Natural Program on Basic Research Project of Shanxi (Grant no. 2015JM5175) 


\section{References}

1. Burdine, N.T. 1963. Rock failure under dynamic loading conditions, Soc Petr Eng J 3(1): 1-8. http://dx.doi.org/10.2118 /481-PA.

2. Li, N.; Chen, W.; Zhang, P.; Swoboda, G. 2001. The mechanical properties and a fatigue-damage model for jointed rock masses subjected to dynamic cyclical loading, Int J Rock Mech Min Sci 38(7): 1071-1079. http://dx.doi.org/10.1016/S1365-1609(01)00058-2.

3. Li, N.; Zhang, P.; Chen S.Y.; Swoboda, G. 2003. Fatigue properties of cracked, saturated and frozen sandstone samples under cyclic loading, Int J Rock Mech Min Sci 40(1): 145-150. http://dx.doi.org/10.1016/S1365-1609(02)00111-9.

4. Enlong, L.; Siming, H. 2012. Effects of cyclic dynamic loading on the mechanical properties of intact rock samples under confining pressure conditions, Engineering Geology 125(27): 81-91.

http://dx.doi.org/10.1016/j.enggeo.2011.11.007.

5. Lajtai, E.Z.; Scott Duncan, E.J; Carter, B.J. 1991.The effect of strain rate on rock strength, Rock Mech Rock Eng 24(2): 99-109.

http://dx.doi.org/10.1007/BF01032501.

6. Chen, E.P.; Taylor, L.M. 1986. Fracture of brittle rock under dynamic loading conditions, In: Barta RC, Evans AG, Hasselman DPH, Lange FF editors. Fracture mechanics of ceramics. New York: Plenum Press 175-86,

7. Addiego, F.; Dahoun, A.; G'Sell, C. 2006. Characterization of volume strain at large deformation under uniaxial tension in high-density polyethylene, Polymer 47: 4387-4399.

http://dx.doi.org/10.1016/j.polymer.2006.03.093.

8. Quatravaux, T.; Elkoun, S.; G'Sel, C. 2002. Experimental characterization of the volume strain of poly (vinylidene fluoride) in the region of homogeneous plastic deformation, J. Polym. Sci. Part B 40: 2516-2522.

http://dx.doi.org/10.1002/polb.10318.

9. Lazzeri, A.; Thio, Y.S.; Cohen, R.E. 2004. Volume strain measurements on $\mathrm{CaCO} 3 /$ polypropylene particulate composites: the effect of particle size, J. Appl. Polym. Sci 91(2): 925-935.

http://dx.doi.org/10.1002/app.13268.

10. Tschoeg, N.W.; Knauss, W.G.; Emri,I. 2002. Poisson's ratio in linear viscoelasticity-a critical review, Mech. Time-Depend. Math 6(1): 3-51. http://dx.doi.org/10.1023/A:1014411503170.

11. Jesus, I.S.; Machado, J.A.T. 2009. Implementation of fractional-order electromagnetic potential through a genetic algorithm, Commun. Nonlinear Sci. Numer. Simul 14: 1838-1843. http://dx.doi.org/10.1016/j.cnsn.2008.015.

12. Lazopoulos, K.A. 2006. Non-local continuum mechanics and fractional calculus, Mech. Res. Comm 33: 753-757. http://dx.doi.org/10.1016/j.mechrescom.2006.05.001.

13. Chen, Y.; Ahn, H.; Podlubny, I. 2006. Robust stability check of fractional order linear time invariant systems with interval uncertainties, Signal Processing 86(10): 2611-2618.

14. Chen, Y.; Vinagre, B.M. 2006. A new IIR-type digital fractional order differentiator, Signal Processing
83(11): 2359-2365.

http://dx.doi.org/10.1016/S0165-1684(03)00188-9.

15.Schmidt, A.; Gaul, L. 2006. On the numerical evaluation of fractional derivatives in multi-degreeof-freedom systems, Signal Processing 86(10): 2592-2601. http://dx.doi.org/10.1016/j.sigpro.2006.02.006.

16. Ray, S.S.; Chaudhuri, K.S.; Bera, R.K. 2006. Analytical approximate solution of nonlinear dynamic system containing fractional derivative by modified decomposition method, Appl. Math. Comput 182(1): 544-552. http://dx.doi.org/10.1016/j.amc.2006.04.016.

17. Enelund, M.; Olsson, P. 1999. Damping described by fading memory-analysis and application to fractional derivative models, Int. J. Solids Struct 36(7): 939-970. http://dx.doi.org/10.1016/S0020-7683(97)00339-9.

18. Shen, F.; Tan, W.; Zhao, Y. 2006. The Rayleigh-Stokes problem for a heated generalized second grade fluid with fractional derivative model, Nonlinear Anal RWA 7: 1072-1080.

19. Sorrentino, S.; Fasana, A. 2007. Finite element analysis of vibrating linear systems with fractional derivative viscoelastic models, J. Sound Vib 299(4): 839-853. http://dx.doi.org/10.1016/j.jsv.2006.07.027.

20. Deshun, Y.; Ruifan, M.; Xiaomeng, D.; Yanqing, L. 2014. Mechanism of complicated volume deformation in polymers and its fractional time-based description, Physica A. 404: 1-7.

http://dx.doi.org/10.1016/j.physa.2014.02.069.

21. Park, S.W. 2001. Analytical modeling of viscoelastic dampers for structural and vibration control, Int. J. Solids Struct 38(44-45): 8065-8092. http://dx.doi.org/10.1016/S0020-7683(01)00026-9.

22. Lewandowski, R.; Chorażyczewski, B. 2010. Identification of the parameters of the Kelvin-Voigt and the Maxwell fractional models, used to modeling of viscoelastic dampers, Comput. Struct 88(1-2): 1-17. http://dx.doi.org/10.1016/j.compstruc.2009.09.001.

23. Rossikhin, Y.A.; Shitikova, M.V.; Shcheglova T.A. 2010. Analysis of free vibrations of a viscoelastic oscillator via the models involving several fractional parameters and relaxation/retardation times, Comput. Math. Appl 59(5): 1727-1744.

http://dx.doi.org/10.1016/j.camwa.2009.08.014.

24. Rossikhin, Y.A.; Shitikova, M.V. 2006. Analysis of damped vibrations of linear viscoelastic plates with damping modeled with fractional derivatives, Signal Processing 86(10): 2703-2711.

http://dx.doi.org/10.1016/j.sigpro.2006.02.016.

25. Rossikhin, Y.A.; Shitikova, M.V. 2001. A new method for solving dynamic problems of fractional derivative viscoelasticity, Internat. J. Engrg. Sci 39(2): 149-176. http://dx.doi.org/10.1016/S0020-7225(00)00025-2.

26. Rossikhin, Y.A.; Shitikova, M.V. 1997. Application of fractional operators to the analysis of damped vibrations of viscoelastic single-mass systems, J. Sound Vib 199(4): 567-586. http://dx.doi.org/10.1006/jsvi.1995.9988.

27. Shan, L.; Tong, D.; Xue, L. 2009. Unsteady flow of non-Newtonian visco-elastic fluid in dual-porosity media with the fractional derivative, J. Hydrodyn. Ser. 
B 21(5): 705-713. http://dx.doi.org/10.1016/S1001-6058(08)60203-6.

28. Ezzat, M.A. 2010. Thermoelectric MHD nonNewtonian fluid with fractional derivative heat transfer, Physica B: Condens. Matter 405: 4188-4194. http://dx.doi.org/10.1016/j.icheatmasstransfer.2016.04. 026.

29. Mahmood, A.; Parveen, S.; Ara, A.; Khan, N.A. 2009. Exact analytic solutions for the unsteady flow of a non-Newtonian fluid between two cylinders with fractional derivative model, Commun. Nonlinear Sci. Numer. Simul. 14: 3309-3319. http://dx.doi.org/10.1016/j.cnsn.2009.01.017.

30. Kilbas, A.A.; Srivastava, H.M.; Trujillo, J.J. 2006. Theory and Applications of Fractional Differential Equations, Amsterdam: Elsevier

31. Hucka, V.; Das, B. 1974. Brittleness determination of rocks by different methods, Int J Rock Mech Min Sci Geomech Abstr 11: 389-92.

http://dx.doi.org/10.1016/0148-9062(74)91109-7.
Mingming He, Ning Li, Yunsheng Chen, Caihui Zhu

A VOLUME DEFORMATION MODEL FOR BRITTLE ROCK BASED ON FRACTIONAL ORDER CALCULUS

S u m m a r y

In compression and tension of brittle rock, the dilatancy phenomena of volume deformation were often observed. This paper presents experimental investigation of volume deformation properties of brittle rock samples in triaxial compression and uniaxial tension tests in different strain rate and different temperature in the laboratory. Based on the viscoelasticity mechanics principle, it is found that the combined effects of elastic and viscoelastic are the basic reason of causing the dilatancy in brittle rock. Moreover, In order to depict the dilatancy phenomena of volume deformation through a simple model presented and have a correct modelization of mechanical behaviors, a volume deformation model is proposed, in which the variation of volume deformation resulted from the combined effects is characterized through a fractional order calculus expression. Comparison between fitting results and experimental results reveals the presented model can describe the dilatancy phenomena of volume deformation of brittle rock.

Keywords: Volume deformation; dilatancy phenomena; Brittle rock; Fractional calculus; Mode.

Received June 17, 2016 Accepted August 04, 2017 